Original Research

\title{
The Effects of Acceptance and Commitment Therapy (ACT) on Depression in TB-HIV Co-infection Patients
}

\author{
Avin Maria1, Untung Sujianto², and Niken Safitri Dyan Kusumaningrum² \\ ${ }^{1}$ Master Program in Nursing, Diponegoro University, STIKES Panti Rapih, Jogjakarta, Indonesia \\ ${ }^{2}$ Lecturer of Nursing Department, Faculty of Medicine, Diponegoro University, Semarang, Indonesia
}

\begin{abstract}
Introduction: The most common psychological problem in TB-HIV coinfection patients is depression. Acceptance and Commitment Therapy (ACT) is an intervention that encourages participants to change their relationships with their thoughts and physical sensations through mechanisms of acceptance and valuebased action. This present study has been carried out to investigate the effectiveness of ACT in treating TB-HIV coinfection patients.
\end{abstract}

Methods: This research was a quasi-experiment. This study involved 62 respondents diagnosed TB-HIV coinfection by doctor, experienced mild depression to severe depression, able to communicate well and have not hearing loss. ACT was given by a researcher with six sessions) one session per day) held in the intervention group. Data were collected using Beck Depression Inventory (BDI) questionnaires. Data analysis use paired t-test to determine the differences in value of depression on pre-test and post-test in each group. Data were analyzed using the independent $\mathrm{t}$-test to determine the effect of ACT on depression.

Results: The majority of respondents were male (66.1\%). Most of the early adult and older adult respondents had moderate depression, while middle-aged adult mostly had severe depression (50\%). The fully unemployed respondents had severe depression (100\%). The analysis results showed that there was a more significant decrease in depression in the intervention group given ACT compared to the control group ( $\mathrm{p}$ value $=0.00$ ).

Conclusion: ACT has an effect on reduce depression of TB-HIV coinfection patients. ACT is recommended to be developed as a nursing intervention that can be given to patients who are depressed.

\section{ARTICLE HISTORY}

Received: February 7, 2020

Accepted: May 9, 2020

\section{KEYWORDS}

depression; TB-HIV coinfection; aceptance and commitment therapy

\section{CONTACT}

Avin Maria

$\triangle$ maria.avin@gmail.com

$\equiv$ Master Program in

Nursing, Diponegoro

University, STIKES Panti

Rapih, Jogjakarta, Indonesia

Cite this as: Maria, A., Sujianto, U., \& Kusumaningrum, N.S.D. (2020). The Effects of Accepance and Commitment Therapy (ACT) on Depression in TB-HIV Co-infection Patients. Jurnal Ners, 15(1). 66-71. doi:http://dx.doi.org/10.20473/in.v15i1.17793

\section{INTRODUCTION}

HIV/AIDS is one of the most devastating illness that people have ever faced (Bhatia \& Munjal, 2014). HIV/AIDS is still a global health problem (Tran et al., 2019). Prevalence of people with HIV/AIDS in the world until end 2018 was recorded as many as 37.9 million people (UNAIDS, 2019). HIV/AIDS will cause the immune system to weaken so that the CD4 count will decrease. As a result, HIV/AIDS patients become more susceptible to various diseases, especially infectious diseases (opportunistic infections). Opportunistic infections that most often occur in people living with HIV/AIDS is tuberculosis (TB). TB remains the leading cause of death among people living with HIV, accounting for around one in three AIDS related deaths. The TB virus will actively develop when the immune system damage gets heavier when the condition of patients with HIV/AIDS have a CD4 count below 200 (Maartens et al., 2014).

In the individual host, the two pathogens, Mycobacterium tuberculosis and HIV, potentiate each other, accelerating the deterioration of immunological functions. Both TB and HIV are heavily stigmatized diseases, and diagnoses may lead to poor psychological health outcomes (Bruchfeld et al., 2015). 
Depression is the most common psychological disorder with TB-HIV (Larson et al., 2017). Depression characterized by persistent sadness and a loss of interest in activities that people normally enjoy, accompanied by an inability to carry out daily activities, poor concentration, pessimistic thoughts and biological symptoms (poor appetite and sleep difficulties) (Kim et al., 2015; Tran et al., 2019). The incidence of depression in TB-HIV patients is $28 \%$ (Deribew et al., 2013). Despite its prevalence, depression is commonly underdiagnosed and consequently untreated in general medical population (Bhatia \& Munjal, 2014).

Depression causes patients to be less likely to adhere to the consultation schedule, poor HIV treatment outcomes, not adhere to therapeutic doses, drug, and alcohol abuse (Gebrezgiabher et al., 2019; Todd et al., 2017; Uthman et al., 2014). This will cause the patient's immune status to decrease. The final impact, the mortality rate will increase (Larson et al., 2017).

Interventions to deal with depression have been carried out, namely Cognitive Behavior Therapy (CBT) (Mohamadian et al., 2018), Internet-based intervention (Karyotaki, 2018), Logo Therapy (Mohammadi et al., 2014), Psychotherapy and Exercise study (Lofgren et al., 2018). Acceptance and Commitment Ther apy (ACT) is one of the interventions for reduce depression that has been developed by Zettle \& Hayes in 1986. ACT helps someone to reduce the problems experienced by increasing the patients awareness and abilities of what they want in their life and aims to improve functioning and quality of life by increasing psychological flexibility (Bramwell \& Richardson, 2018).

ACT is as effective as other established psychological interventions in treating depression (ATjak et al., 2015). In ACT, depression is conceptualized as a secondary emotion that arises from struggling to avoid normal and adaptive emotional reactions to distressing life events, for example, loss (Far, Gharraee, Birashk, \& Habibi, 2017). The core difference between ACT and other interventions is the central proposition that diagnostically distinct clinical disorders may be established and maintained through common processes that are rooted in the capacity for language. These common processes include psychologically deleterious experiential avoidance (Bai, Luo, Zhang, $\mathrm{Wu}, \& \mathrm{Chi}$, 2020), which has been defined as an unwillingness to experience feelings, physiological sensations, and thoughts, especially those that are negatively evaluated, as well as attempts to alter the form or frequency of these events and the contexts that occasion them (Twohig, 2012).
A recent meta-analysis concluded that ACT was effective to reduce depression in personality disorder patient, mental disorder patient, cancer patient, male smokers, and university students. In this study, ACT was given between four weeks until 16 weeks. The session was given once or twice per week (Bai et al., 2020). There have been several studies of ACT to reduce depression, especially in mental disorder outpatients. However, study about ACT on TB-HIV patients has never been done before. Therefore, in the present study, the aim is to investigate the effectiveness of Acceptance and Commitment Therapy (ACT) in treating depression in TB-HIV coinfection inpatients.

\section{MATERIALS AND METHODS}

This study was a quasi-experimental method with a pre-test and post-test design with comparison group design, which was conducted from December 2018 until February 2019. Before data collection, this study obtained ethics approval from Aisyiyah University, Yogyakarta (No. 727/KEP-UNISA/XII/2018).

The population in this study was TB-HIV coinfection patients who were hospitalized in Yogyakarta Regional Public Hospital and Sleman Regional Public Hospital. The sample was selected through the consecutive sampling method and divided into two groups, the experimental group and the control group. The inclusion criteria were patients who have been diagnosed TB-HIV coinfection by doctor, experienced mild depression to severe depression, and able to communicate well. The exclusion criterion was patients who have hearing loss.

The number of people in each group was 31 people. The experimental group members participated in six sessions (one session per day). Each session was given in 60 minutes. They were also given ACT module. No intervention was done in the control group by the researcher. However, the control group still received usual care from hospital. After data collection was done, the control group was also explained about ACT and given the ACT module. It was expected that this study has applied the principle of justice.

The ACT sessions are 1) Acceptance (willingness to open fully to unwanted experiences such as difficult thoughts, memories, or emotions); 2) Cognitive defusion (being able to step back from unwanted experiences without getting stuck in them); 3) Present moment (being mindful and aware of one's experiences); 4) Self as a context (maintaining perspective about oneself within one's experiences); 5) Valuing (staying connected to personal values or areas of life that are important) and 6) Commitment (engaging in actions that move toward important aspects of life).

Data were collected using Beck Depression Inventory (BDI) Indonesia Version questionnaires that consist of cognitive, affective and somatic 
Table 1. Distribution of Both Groups regarding Their Sociodemographic Characteristics

\begin{tabular}{|c|c|c|c|c|}
\hline Characteristics & Intervention $(\mathrm{n}=31)$ & Control $(n=31)$ & Total $(n=62)$ & $\mathbf{p}$ \\
\hline Characteristics & n (\%) & n (\%) & $n(\%)$ & \\
\hline Gender & & & & 0.125 \\
\hline Male & $19(61.3 \%)$ & $22(71 \%)$ & $41(66.1 \%)$ & \\
\hline Female & $12(38.7 \%)$ & $9(29 \%)$ & $21(33.9 \%)$ & \\
\hline Age & & & & 0.425 \\
\hline Early Adult (18-40 years) & $20(64.5 \%)$ & $18(58.1 \%)$ & $38(61,2 \%)$ & \\
\hline Middle Adult (41-60 years) & $7(22.6 \%)$ & $11(35.5 \%)$ & $18(29.1 \%)$ & \\
\hline Late Adult ( $>60$ years) & $4(12.9 \%)$ & $2(6.5 \%)$ & $6(9.67 \%)$ & \\
\hline Marital Status & & & & 0.932 \\
\hline Single & $13(41.9 \%)$ & $16(51.6 \%)$ & $29(46.7 \%)$ & \\
\hline Widow/widower & $8(25.8 \%)$ & $7(22.6 \%)$ & $15(24.2 \%)$ & \\
\hline Married & $10(32.3 \%)$ & $8(25.8 \%)$ & $18(29.1 \%)$ & \\
\hline Education & & & & 0.353 \\
\hline Elementary School & $5(16.1 \%)$ & $3(9.7 \%)$ & $8(13 \%)$ & \\
\hline Junior High School & $5(16.1 \%)$ & $5(16.1 \%)$ & $10(16.1 \%)$ & \\
\hline Senior High School & $14(45.2 \%)$ & $15(48.4 \%)$ & $29(46.7 \%)$ & \\
\hline College & $7(22.6 \%)$ & $8(25.8 \%)$ & $15(24.2 \%)$ & \\
\hline Last Job & & & & 0.893 \\
\hline Not yet working & $2(6.5 \%)$ & $1(3.2 \%)$ & $3(4.8 \%)$ & \\
\hline Housewife & $5(16.1 \%)$ & $6(19.4 \%)$ & $11(17.7 \%)$ & \\
\hline Laborer & $8(25.8 \%)$ & $8(25.8 \%)$ & $16(25.8 \%)$ & \\
\hline Entrepreneur & $7(22.6 \%)$ & $7(32.6 \%)$ & $14(22.7 \%)$ & \\
\hline PNS/TNI/POLRI & $2(6.5 \%)$ & $0(0 \%)$ & $2(3.2 \%)$ & \\
\hline Private & $7(22.6 \%)$ & $9(29.0 \%)$ & $16(25.8 \%)$ & \\
\hline Complications of the disease & & & & 0.233 \\
\hline Yes & $8(25.8 \%)$ & $6(19.4 \%)$ & $14(22.7 \%)$ & \\
\hline No & $23(74.2 \%)$ & $25(80.6 \%)$ & $48(77.3 \%)$ & \\
\hline
\end{tabular}

Table 2. Difference in BDI Scores on Pre-test and Post-test of Experimental Group and Control Group

\begin{tabular}{|c|c|c|c|c|c|}
\hline Variable & Group & & Mean & SD & P Value \\
\hline \multirow{4}{*}{ Depression } & \multirow{2}{*}{ Experimental group } & Pre-test & 20,38 & \multirow{2}{*}{6,34} & \multirow{2}{*}{0,000} \\
\hline & & Post-test & 12,29 & & \\
\hline & \multirow[t]{2}{*}{ Control group } & Pre-test & 21,38 & \multirow[t]{2}{*}{1,50} & \multirow[t]{2}{*}{0,293} \\
\hline & & Post-test & 21,67 & & \\
\hline
\end{tabular}

Table 3. Distribution of Experimental and Control Group Regarding Indicator of BDI in Post-test

\begin{tabular}{lcccccc}
\hline \multirow{2}{*}{ Variable } & \multicolumn{2}{c}{ Experimental Group } & \multicolumn{2}{c}{ Control Group } & \multirow{2}{*}{ P value } \\
\cline { 2 - 5 } & & Mean & SD & Mean & SD & \\
\hline Depression & 12.29 & 4.93 & 21.67 & 4.52 & 0.000 \\
\hline
\end{tabular}

depression symptoms with content validity item in the range of 0.51 and Cronbach's alpha value 0.90 . The data were recapitulated, entered into SPSS program and analyzed. One Way ANOVA test was used to identify homogeneity of respondents' characteristics. Data analysis using paired t-test was used to determine the differences value of depression on pre-test and post-test in each group. Data analysis using independent t-test was used to determine the effect of ACT on depression in both groups.

\section{RESULTS}

Characteristics of respondents in this research are majority was male $(66.1 \%)$ in both the experimental group and the control group. The majority of respondents were early adult, both in the experimental group (64.5\%) and the control group $(58.1 \%)$. Based on the marital status, the majority of respondents had single status (46.7\%). Based on education, majority respondents had a senior high school education. Based on the presence of disease complications, more than half of the control group $(80.6 \%)$ and experimental group $(74.2 \%)$ had no complications of the disease. All of the respondents' characteristics have $p$ value $>0.05$, which means that both groups are homogeneous (Table 1 ).

Table 2 shows the results of the analysis of BDI scores on pre-test and post-test which found a significant reduction in depression symptoms in the experimental group that was equal to $8.09(\mathrm{p}=0.00)$. A greater reduction was found in the experimental group where the BDI scores mean before the ACT intervention was at 20.38 (moderate depression) and after the intervention, the BDI scores mean decreased to 12.29 (mild depression).

The control group had a BDI score mean of 21.38 (moderate depression) on pre-test and the average actually increased to 21.67 (moderate depression) on post-test. The average value actually increased by 0.29 with $p$ value $=0.329(>0.05)$. Based on these 
data, it can be concluded that there was a significant change in the condition of depression pre-test and post-test only in the experimental group.

The effect of Acceptance and Commitment Therapy (ACT) for reducing depression can be seen from the mean post-test scores in the intervention group and the control group (Table 3 ). Table 2 shows the difference in BDI scores in the control and experimental group after getting ACT. It can be said that there is a significant difference in the experimental and control groups among depression $(p=0.000)$. Given the size of this effect, the rate is significant. Therefore, it can be said that Acceptance and Commitment Therapy (ACT) significantly reduces depression in TB-HIV coinfection patients.

\section{DISCUSSION}

In the current study, the effectiveness of Acceptance and Commitment Therapy to reduce depression was investigated and the finding was positive. This result is consistent with the findings of previous studies. Heydari, Masafi, Jafari, Saadat, and Shahyad. (2018) showed that Acceptance Commitment Therapy for Razi Psychiatric Center staff had a positive effect on decreasing anxiety and depression (Heydari et al., 2018). Other study found that ACT was positive for relieving depression for patients with mild depression and depressed adults; depressive symptoms reduced significantly immediately after the intervention as well as at the three months of follow up (Bai et al., 2020).

In acceptance and commitment therapy, depression conceptualization is emotions related to past events, such as death or losing something, which prevents normal reactions and adaptation to stressful life events. In the above approach, the content of a depressed person's negative thoughts is not considered. The ACT intervention led to statistically significant reduction in depressive symptomatology. Moreover, mediational analysis showed that the improvement of acceptance during the intervention mediated the effects of the intervention on depressive symptomatology at follow-up (Bohlmeijer, Fledderus, Rokx, \& Pieterse, 2011).

The decrease in BDI scores in the experimental group could be caused by ACT. This could occur because, through ACT, respondents were asked to make commitments. The commitment states what is important to the individual and when making a commitment the respondent will underline the choices made, thereby committing to influence the emotional response and coping of individual to react to the presence of stressors (Hayes \& Waltz, 2010). This is in accordance with the results of the research obtained where, after receiving ACT treatment, the mean of BDI scores decreased up to 11.08. Majority respondents were in moderate level of depression on pre-test, while on post-test, majority respondents were in mild level of depression.

The mean of BDI score in the control group actually increased before and after treatment, from
21.38 to 21.67 . According to observations, the level of depression increase that occurred in the control group respondents could be due to the length of stay. In the control group respondents, the majority underwent hospitalization for 8-10 days. This is consistent with previous research which states that depression can occur because of the length of stay of hospitalization. When patients undergo lengthy hospitalization, they experience conditions that result in a person's inability to relate interpersonally. Depression can be felt if individuals have a sensitivity to the environment. The existence of conditions such as separation from the closest person or loss of something can cause a person to experience depression (Nasronudin, 2012).

Evaluation of the level of depression after giving ACT was done by giving a questionnaire to the respondents and observations made directly by the researcher. According to observations, when ACT was first performed, the majority of respondents avoided telling stories or meeting face-to-face with researchers. The avoidance of being able to be open in conveying the burden and the problem experienced (experiential avoidance) can be caused by cognitive defusion in that the environment will be judged poorly if it conveys its burden too far. This is an indicator of the absence of psychological flexibility (the ability to think with several different concepts) in respondents. Without realizing it, avoiding behavior chosen as a strategy used, but is not effective for the long term. This is reflected in the reaction of respondents who are increasingly depressed because they feel alone in dealing with their illness (Bai et al., 2020).

In the third session 'present moment', the psychological knowledge of subjects was added. This means that the individuals were aware of all mental states, thoughts, and behavior in the present moment. Fourth session, 'self as a context', involved efforts to reduce the excessive focus on visualization or personal story (as victims) that the individuals had made for themselves. Fifth, 'valuing', was about helping the individuals to understand their basic personal values and identify them to convert to specific behavioral goals (to clarify the values). Finally, the last session 'commitment', involved motivating them to act responsibly toward the goals and values of the activities identified with the adoption of mental experiences. (Farb et al., 2018; Montgomery, Kim, \& Franklin,, 2011).

Because of these conditions, the ACT is important. ACT made it clear to respondents that it was important to provide space for themselves to accept unpleasant feelings and experiences so that they did not need to be avoided, and appreciation of other people's judgments that were not necessarily attached to them. ACT also made the respondents aware of the important things and expectations in life, and that it can change the perspective of the respondent in seeing the situation, and reduce the attachment to negative thoughts and feelings (Rauwenhoff, Peeters, Bol, \& Van HeugtenVan, 2019). 
This was proven in that, after the second meeting to the end, respondents felt happy and more open.

With the growing willingness to face and undergo the consequences obtained through ACT, there is a change in the cognition process where appraisal of situations that cause depression is no longer seen as something negative. When the meaning changes, which initially becomes negative neutral, the appraisal will change and the level of depression will also decrease. ACT also directs to improve their perspective to be more positive in dealing with problems through coping changes based on the emotions felt. The aim of ACT is to change the functions and context of behavior and thoughts; symptom reduction is not a treatment outcome (Hayes \& Waltz, 2010).

Through ACT, the respondents were not only invited to accept, but were also facilitated to be able to set steps to overcome their problems along with the acceptance of the consequences. With the establishment of these measures, perceived resources can more reach demands as TB-HIV coinfected patients. Thus, this can reduce the level of depression experienced (Syndrome, Maghsoudi, Razavi, Razavi, \& Javadi, 2019).

This study has some limitations. First, these findings are based on self - reporting of people. Second, this study did not have follow-up period. Third, the lack of large sample size of the population and only at two hospitals could be mentioned as other potential limitation. Finally, further studies with larger sample sizes in multi-centers are suggested to clarify the results of this study. Follow-up post-test in longer period is needed, for example within one month after intervention. This is intended to know whether ACT has an effect on reducing depression in the long term. Investigating the effects of ACT on other patient outcomes such as quality of life, coping, adherence to treatment is recommended as is analyzing the patterns of all aspects of ACT on depression. It can be concluded that Acceptance and Commitment Therapy could reduce depression.

\section{CONCLUSION}

There was a significant difference between the value of depression in the experimental group after being given Acceptance and Commitment Therapy compared to the control group. This means that ACT has the effect of reducing depression in TB-HIV coinfection patients. ACT is recommended to be developed as a nursing intervention that can be given to patients who are depressed. Nurses can now directly use ACT to intervene according to the actual situation, so as to improve service efficiency and effects.

\section{REFERENCES}

A-Tjak, J.G., Davis, M.L., Morina, N., Powers, M.B., Smits, J.A.J., \& Emmelkamp, P.M.G. (2015). A Meta Analysis of the Efficacy of Acceptance and Commitment Therapy for Clinically Relevant
Mental and Physical Health Problems. Psychotherapy and Psychosomatics, 84, 30-36. https://doi.org/10.1159/000365764

Bai, Z., Luo, S., Zhang, L., Wu, S., \& Chi, I. (2020). Acceptance and Commitment Therapy (ACT) to Reduce Depression: A Systematic Review and Meta-analysis. Journal of Affective Disorders, 260(May 2019), 728-737. https://doi.org/10.1016/j.jad.2019.09.040

Bhatia, M.S., \& Munjal, S. (2014). Prevalence of depression in people living with HIV/AIDS undergoing art and factors associated with it. Journal of Clinical and Diagnostic Research, 8(10), 1-4. https://doi.org/10.7860/JCDR/2014/7725.4927

Bohlmeijer, E.T., Fledderus, M., Rokx, T. A.J.J., \& Pieterse, M.E. (2011). Efficacy of an Early Intervention Based on Acceptance and Commitment Therapy for Adults with Depressive Symptomatology: Evaluation in a Randomized Controlled Trial. Behaviour Research and Therapy, 49(1), 62-67. https://doi.org/https://doi.org/10.1016/j.brat.2 010.10.003

Bramwell, K., \& Richardson, T. (2018). Improvements in Depression and Mental Health After Acceptance and Commitment Therapy are Related to Changes in Defusion and Values-Based Action. Journal of Contemporary Psychotherapy, 48(1), 9-14. https://doi.org/10.1007/s10879-017-9367-6

Bruchfeld, J., Correia-Neves, M., \& Kallenius, G. (2015). Tuberculosis and HIV Coinfection. Cold Spring Harbor Perspectives in Medicine, 5(7), 1-15. https://doi.org/10.1101/cshperspect.a017871

Deribew, A., Deribe, K., Reda, A.A., Tesfaye, M., Hailmichael, Y., \& Maja, T. (2013). Do common mental disorders decline over time in TB/HIV coinfected and HIV patients without TB who are on antiretroviral treatment? BMC Psychiatry, 13(1), 1. https://doi.org/10.1186/1471-244X-13-174

Far, S.T., Gharraee, B., Birashk, B., \& Habibi, M. (2017). Effectiveness of acceptance and commitment therapy and cognitive therapy in patients with major depressive disorder. Iranian Journal of Psychiatry and Behavioral Sciences, 11(4). https://doi.org/10.5812/ijpbs.3459

Farb, N., Anderson, A., Rayindran, A., Hawley, L., Irving, J., Mancuso, E,... Segal, Z.V. (2018). Prevention of relapse/recurrence in major depressive disorder with either mindfulnessbased cognitive therapy or cognitive therapy. Journal of Consulting and Clinical Psychology, 86(2), 200-204. https://doi.org/https://doi.org/10/1037/ccp00 00266

Gebrezgiabher, B.B., Abraha, T.H., Hailu, E., Siyum, H., Mebrahtu, G., Gidey, B.,... Angesom, T. (2019). Depression among Adult HIV/AIDS Patients Attending ART Clinics at Aksum Town, Aksum, Ethiopia: A Cross-Sectional Study. Depression Research and Treatment, 2019. https://doi.org/10.1155/2019/3250431 
Hayes, S., \& Waltz, T. (2010). Acceptance and Commitment Theraphy In Cognitive Behavioral Therapy in Clinical Practice. The Guilford Press.

Heydari, M., Masafi, S., Jafari, M., Saadat, S.H., \& Shahyad, S. (2018). Effectiveness of Acceptance and Commitment Therapy on Anxiety and Depression of Razi Psychiatric Center Staff. Public Health,

15. https://doi.org/10.3889/oamjms.2018.064

Karyotaki, E. (2018). Internet Based Interventions for People wih HIV and Depression. Lanset, 5(9), 474 475. https://doi.org/10.1016/S23523018(18)30172-3

Kim, J.L., Cho, J., Park, S., \& Park, E.C. (2015). Depression symptom and professional mental health service use. BMC Psychiatry, 15(1), 1-12. https://doi.org/10.1186/s12888-015-0646-z

Larson, H., Moverman, H., Saito, S., Frederix, K., Pitt, B., Maime, M., \& Howard, A.A. (2017). Depressive Symptoms and Hazardous/Harmful Alcohol Use are Prevalent and Correlate with Stigma among TB-HIV Patients in Lesotho. Physiology \& Behavior, 176(1), 139-148. https://doi.org/10.1016/j.physbeh.2017.03.040

Lofgren, S.M., Nakasujja, N., \& Boulware, D.R. (2018). Systematic Review of Interventions for Depression for People Living with HIV in Africa. AIDS and Behavior, 22(1), 1-8. https://doi.org/10.1007/s10461-017-1906-3

Maartens, G., Ceum, C., \& Lewin, S.R. (2014). HIV Infection: Epidemiology, Pathogenesis, Treatment, and Prevention. Lanset, 384, 2014 258-271. https://doi.org/10.1016/S01406736(14)60164-1

Mohamadian, F., Bagheri, M., Hashemi, M.S., \& Komeili Sani, H. (2018). The Effects of Cognitive Behavioral Therapy on Depression and Anxiety among Patients with Thalassemia: a Randomized Controlled Trial. Journal of Caring Sciences, 7(4), 219-224. https://doi.org/10.15171/jcs.2018.033

Mohammadi, F., Fard, F.D., \& Heidari, H. (2014). Effectiveness of Logo Therapy in Hope of Life in The Women Depression. Social and Behavioral Sciences, 159, $643 \quad$ - 646. https://doi.org/10.1016/j.sbspro.2014.12.440
Montgomery,K.L., Kim, J, S., \& FranklinC. (2011). Acceptance and Commitment Therapy: for Physiological and Psychological Illness. National Association of Social Worker.

Nasronudin. (2012). HIV \& AIDS. Pendekatan Biologi Molekuler, Klinis dan Sosial. Airlangga University Press.

Rauwenhoff, J., Peeters, F., Bol, Y., \& Van Heugten, C. (2019). The Brain ACT study: acceptance and commitment therapy for depressive and anxiety symptoms following acquired brain injury: study protocol for a randomized controlled trial. BMC, 20(773), 1-10. https://doi.org/10.1186/s13063019-3952-9

Syndrome, M., Maghsoudi, Z., Razavi, Z., Razavi, M., \& Javadi, M. (2019). Efficacy Of Acceptance And Commitment Therapy For Emotional Distress In The Elderly With Type 2 Diabetes : A Randomized Controlled Trial. Dovepress, 12, 2137-2143. https://doi.org/10.2147/DMSO.S221245

Todd, J.V., Cole, S.R., Pence, B.W., Lesko, C.R., Bacchetti, P., Cohen, M. H., \& Adimora, A.A. (2017). Effects of Antiretroviral Therapy and Depressive Symptoms on All-Cause Mortality Among HIV-Infected Women. American Journal of Epidemiology, 185, 869-878. https://doi.org/10.1093/aje/kww192

Tran, B.X., Ho, R.C.M., Ho, C.S.H., Latkin, C.A., Phan, H.T., Ha, G.H.H., ... Zhang, M.W.B. (2019). Depression among Patients with HIV/AIDS: Research Development and Effective Interventions. Environment Research Public Health, 16, 1-15. https://doi.org/10.3390/ijerph16101772 w

Twohig, M. (2012). Acceptance and Commitment Therapy. Cognitive and Behavioral Practice, 19, 499-507. https://doi.org/10.1016/j.cbpra.2012.04.003

UNAIDS. (2019). Global HIV \& AIDS Statistics.

Uthman, O.A., Magidson, J.F., Safren, S.A., \& Nachega, J.B. (2014). Depression and Adherence to Antiretroviral Therapy in Low-, Middle- and HighIncome Countries: A Systematic Review and MetaAnalysis. Current HIV/AIDS Reports, 11, 291-307. https://doi.org/10.1007/s11904-014-0220-1 